\title{
Особенности морфологии и оптических свойств наноструктур дисульфида молибдена от мономолекулярного слоя до фрактолообразной субструктуры
}

\author{
(c) Э.П. Домашевская, Д.Л. Голощапов, Аль Хайлани Хасан Исмаил Дамбос, \\ Е.В. Руднев, М.В. Гречкина, С.В. Рябцев
}

Воронежский государственный университет, 394006 Воронеж, Россия

E-mail: ft@@phys.vsu.ru

Поступила в Редакцию 25 февраля 2019 г. В окончательной редакции 5 марта 2019 г. Принята к публикации 5 марта 2019 г.

Целью работы является показать влияние толщины слоев на особенности морфологии и оптических свойств наноструктур $\mathrm{MoS}_{2}$, в том числе мономолекулярных слоев, образующихся при газотранспортном переносе паров серы в горячую зону реактора с металлическим молибденом и последующем осаждении на подложку из слюды (мускавит). Результаты исследования методами атомной силовой микроскопии АСМ, оптической спектроскопии поглощения и рамановской спектроскопии наноструктур дисульфида молибдена разной толщины, полученных при различных температурах газотранспортного синтеза, показывают, что в интервале температур 525-600 ${ }^{\circ} \mathrm{C}$ можно получить мономолекулярный слой $\mathrm{MoS}_{2}$, содержащий тригональные домены и обладающий шириной запрещенной зоны 1.84 эВ при прямозонном оптическом переходе с образованием экситонов при комнатной температуре. Впервые получены фракталообразные субструктуры, в рамановских спектрах которых значения мод внутрислоевых и межслоевых колебаний $E_{2 g}^{1} 377.5$ и $A_{1 g}$ $403.8 \mathrm{~cm}^{-1}$ отличаются не только от соответствующих значений мод мономолекулярного слоя, но и от известных значений объемных образцов. Частота внутрислоевой моды в этих образцах $E_{2 g}^{1} 377.5 \mathrm{~cm}^{-1}$ имеет минимальное из всех известных значений.

Ключевые слова: дисульфид молибдена, газотранспортный синтез, мономолекулярный слой, прямозонный переход, тригональные домены.

DOI: 10.21883/FTP.2019.07.47871.9090

\section{1. Введение}

Первая работа, посвященная методам получения 2D материалов, была опубликована в 2005 году [1]. В ней продемонстрирован принцип отслоения от трехмерных монокристаллов 2D монослоев не только графена, но и других соединений со слоистой структурой, в том числе, дихалькогенидов переходных металлов. Было показано, что с помощью методики механического отслаивания (эксфолиации) можно получить контролируемое количество атомных/молекулярных слоев в дисульфиде молибдена $\mathrm{MoS}_{2}$ и других дихалькогенидах переходных металлов (ДПМ). При этом с уменьшением числа слоев изменяется не только ширина запрещенной зоны, но и кристаллическая структура. Эти материалы стоят относительно недорого. Они проявляют специфические оптические свойства, в них возможны оптические переходы между долинами с изменением спина электронов [2].

ДПМ $\mathrm{MoS}_{2}$ и $\mathrm{WS}_{2}$ в небольших количествах встречаются в земной коре, а в 2016 г. был обнаружен новый минерал, напоминающий свиток, скрученный из листа сульфидов молибдена, свинца, ванадия и сурьмы [3].

На данный момент наиболее перспективными считаются полупроводниковые соединения вольфрама и молибдена с серой и селеном, но самым исследуемым является дисульфид молибдена $\mathrm{MoS}_{2}$ [4-7].
Двумерный мономолекулярный дисульфид молибдена $\mathrm{MoS}_{2}$ (2D) состоит из тройного слоя $\mathrm{S}-\mathrm{Mo}-\mathrm{S}$ и проявляет множество интересных свойств. В то время как объемный $\mathrm{MoS}_{2}$ является непрямозонным полупроводником, в мономолекулярном состоянии он становится прямозонным $[1,4]$, что способствует проявлению фотолюминесценции с чувствительным фотооткликом [2,5]. Кроме того, мономолекулярный слой $\mathrm{MoS}_{2}$ является сверхпрочным материалом [6], чей энергетический зазор может быть легко настроен с помощью деформационной инженерии $[7,8]$. Эти уникальные свойства делают мономолекулярный слой $\mathrm{MoS}_{2}$ идеально подходящим для применений в таких областях, как эффективные фотокатализаторы [7], солнечные элементы [8] и экситонные интегрированные цепи $[9,10]$.

Однако эти приложения требуют крупномасштабных разработок монослоев $\mathrm{MoS}_{2}$, обладающих вышеупомянутыми свойствами. Обычно монослои $\mathrm{MoS}_{2}$ получают посредством метода отслоения от монокристаллов [11-14], что приводит к образованию микромасштабных хлопьев со случайным распределением толщин слоев. В последнее время разработано несколько других методов, таких как сульфидирование металлического молибдена $[15,16]$ или оксида молибдена [17-19], а также разложение тиомолибдатов [20,21], при использовании которых полученные пленки демонстрировали толщину от монослоя до нескольких слоев. 
К настоящему времени известно большое количество работ, посвященных изучению электронной структуры $\mathrm{MoS}_{2}$ как теоретическими, так и экспериментальными методами [22-34]. Электронные свойства ДПМ сильно зависят от количества слоев и их расположения, так как с уменьшением количества слоев происходит переход непрямой запрещенной зоны в прямую. Например, для монослоя $\mathrm{MoS}_{2}$ расщепление кристаллическим полем $d$-орбиталей приводит к прямой запрещенной зоне 1.8 эВ в точке К зоны Бриллюэна. Такой материал может быть использован в фотонных детекторах.

Эффективные массы вблизи точки К равны: $m^{*}=0.54$ для электронов в зоне проводимости и $m^{*}=0.44$ для дырок в валентной зоне [35]. Однако точные величины энергетических зазоров и эффективных масс в мономолекулярном слое $\mathrm{MoS}_{2}$ по-прежнему дебатируются из-за недостатка прямых измерений этих параметров.

Многослойные структуры имеют непрямую щель, соответствующую переходу $\Gamma-\mathrm{K}$ из точки $\Gamma$ валентной зоны в точку К зоны проводимости. Изменение в зонной структуре при изменении количества слоев $\mathrm{MoS}_{2}$ вызвано эффектом квантового туннелирования между слоями и является результатом изменения гибридизации $p z$-орбиталей атомов серы и $d$-орбиталей атомов молибдена.

Цель настоящей работы - показать влияние толщины на особенности морфологии и оптических свойств/ширины запрещенной зоны нанослоев различной толщины $\mathrm{MoS}_{2}$, в том числе мономолекулярного слоя $\mathrm{MoS}_{2}$, образующихся при газотранспортном переносе паров серы в горячую зону реактора с металлическим молибденом и последующим осаждением на стеклянную подложку.

\section{2. Методика эксперимента}

Среди известных методов получения нанослоев дисульфида молибдена преобладает химическое осаждение из газовой фазы (chemical vapor deposition CVD) [36,37].

В нашей предыдущей работе [38] мы показали, что при формировании $\mathrm{MoS}_{2}$ газотранспортным переносом паров серы на металлические пластины молибдена, расположенные в горячей зоне кварцевого реактора, в интервале температур $800-1000^{\circ} \mathrm{C}$, на Мо-пластинах образуются дисульфиды молибдена различных модификаций/политипов: гексагональной $P 6_{3} / m m c$ при $800^{\circ} \mathrm{C}$ и ромбоэдрической (тригональной) $R 3 m$ при $1000^{\circ} \mathrm{C}$.

Таким образом, наш опыт показал, что температура синтеза гексагональных нанослоев $\mathrm{MoS}_{2}$ не должна превышать $800^{\circ} \mathrm{C}$. В настоящей работе мы получали наноструктуры $\mathrm{MoS}_{2}$ различной толщины, начиная с мономолекулярного слоя, в интервале температур $525-600^{\circ} \mathrm{C}$.

В настоящей работе реактор состоял из герметизированной кварцевой трубы, средняя часть которой нагревалась до необходимых температур $525-600^{\circ} \mathrm{C}$ с помощью электрической печи. В средней, высокотемпературной части кварцевой трубы размещалась молибденовая фольга, предварительно очищенная от окислов в соляной кислоте и затем промытая в дистиллированной воде. Через герметизированную кварцевую трубу пропускался поток аргона высокой чистоты с расходом $15-20 \mathrm{~cm}^{3} / \mathrm{Mин}$. В кварцевой трубе, со стороны входа аргона, в температурной зоне $150^{\circ} \mathrm{C}$ была расположена керамическая лодочка с особо чистой серой. Образующиеся пары серы переносились потоком аргона в высокотемпературную область трубы и там взаимодействовали с поверхностью молибденовой фольги. В результате этого взаимодействия на поверхности подложки из слюды (мусковита), расположенной над молибденовой фольгой на расстоянии 3-5 мм, образовывался слой дисульфида молибдена, плотность, морфология и оптические свойства которого зависели от толщины осажденного слоя.

Для изучения морфологии поверхности образцов был использован атомно-силовой микроскоп (АСМ) P47-PRO AFM Solver ЦКП НО ВГУ.

Оптические спектры снимались на двулучевом спектрометре Shimadzu 210A.

Рамановские спектры комбинационного рассеяния регистрировались на спектрометре Raman Microscope RamMics M532 EnSpectr в области $350-3650 \mathrm{~cm}^{-1}$ $\left(\lambda_{\mathrm{ex}}=532 \mathrm{HM}\right)$.

\section{3. Результаты и обсуждение}

\section{1. Морфология поверхности однослойных и многослойных наноструктур $\mathrm{MoS}_{2}$}

Дисульфид молибдена кристаллизуется в слоистой структуре, в которой атомы серы расположены в плотноупакованных гексагональных слоях, а атомы молибдена, расположенные между двумя слоями серы, имеют тригональную призматическую координацию. В объемном $\mathrm{MoS}_{2}$ существуют два политипа, $2 \mathrm{H}$ (гексагональной сингонии) и $3 R$ (ромбоэдрической сингонии), из-за разных последовательностей в расположении слоев $[1,3,39]$. Политип $2 H$ имеет два слоя в элементарной ячейке, уложенной в гексагональной симметрии в последовательности $\mathrm{AbA} / \mathrm{BaB}$ в сечении [1120], и принадлежит к пространственной группе $P 6_{3} / m m c\left(D_{6 h}^{4}\right)$. Верхний регистр последовательности букв обозначает атомы серы, буквы нижнего регистра используются для обозначения атомов молибдена и знак / обозначает силы Ван-дерВаальса между двумя слоями атомов серы.

Политип $R 3 m(3 R)$ имеет три слоя в элементарной ячейке в направлении параметра $c$ (направление [0001]) в ромбоэдрической симметрии с последовательностью $\mathrm{AbA} / \mathrm{BcB} / \mathrm{CaC}$ в сечении [1120] и принадлежит к пространственной группе $R 3 m\left(C_{3 v}^{5}\right)$. Поверхность кристаллов, перпендикулярную к параметру $c$, обычно называется поверхностью Ван-дер-Ваальса.

Толщина одного молекулярного слоя $\mathrm{MoS}_{2}$ равна $6.25 \AA$ А. Поэтому мономолекулярные слои являются почти прозрачными, однако обладают характерной субструктурой и оптическими свойствами прямозонного 


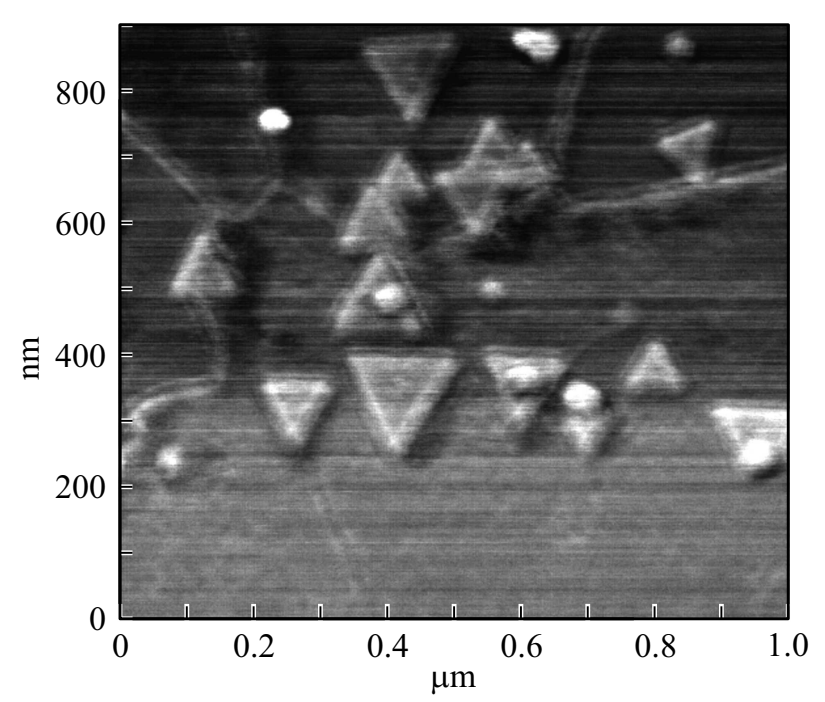

Рис. 1. АСМ-изображение мономолекулярного слоя $\mathrm{MoS}_{2}$ с тригональными доменами.

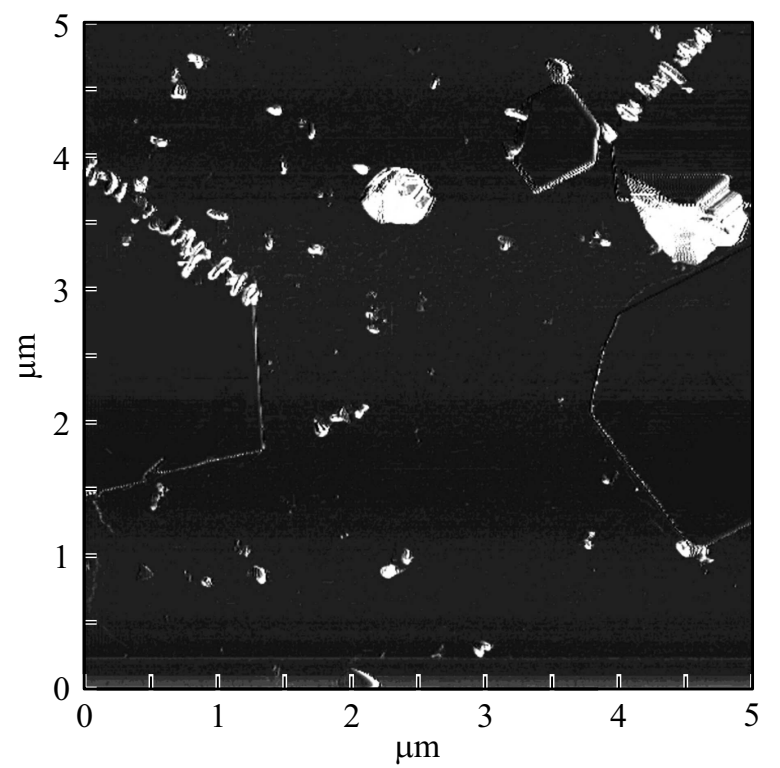

полупроводника, благодаря которым их можно идентифицировать.

Таким образом, при интерпретации всех экспериментальных результатов следует учитывать, что образцы $\mathrm{MoS}_{2}$ с нечетным числом слоев, включая мономолекудярные слои, имеет тригональную симметрию $D_{3 h}$ (без инверсионной симметрии), а образцы $\mathrm{MoS}_{2}$ с четным числом слоев, как и объемный кристалл, имеют гексагональную симметрию $D_{6 h}[40]$.

На рис. 1 приведено АСМ-изображение полученного нами мономолекулярного слоя $\mathrm{MoS}_{2}$, на котором хорошо видны самоорганизованные домены тригональной симметрии, самоподобной тригональной симметрии элементарной ячейки мономолекулярного слоя $D_{3 h}$. Длины сторон доменов в виде правильных треугольников в среднем составляют 100-200 нм.

Полученные в таких же условиях при $600^{\circ} \mathrm{C}$ двуслойные пленки содержат домены гексагональной фор-

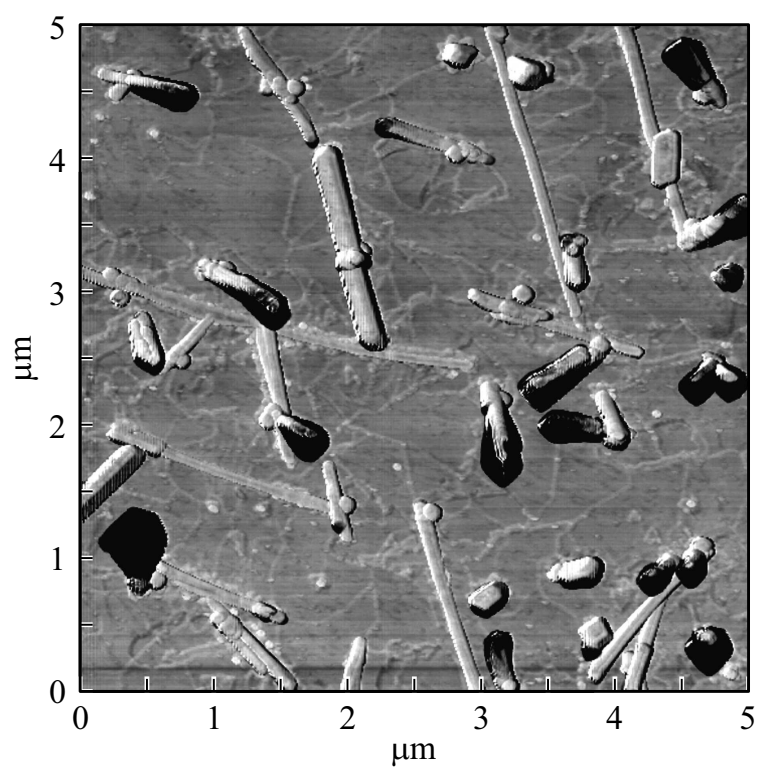

Рис. 2. АСМ-изображения двуслойных $\mathrm{MoS}_{2}$ : слева - гексагональные домены микронных размеров; справа - нанотрубки из поверхностного слоя $\mathrm{MoS}_{2}$.
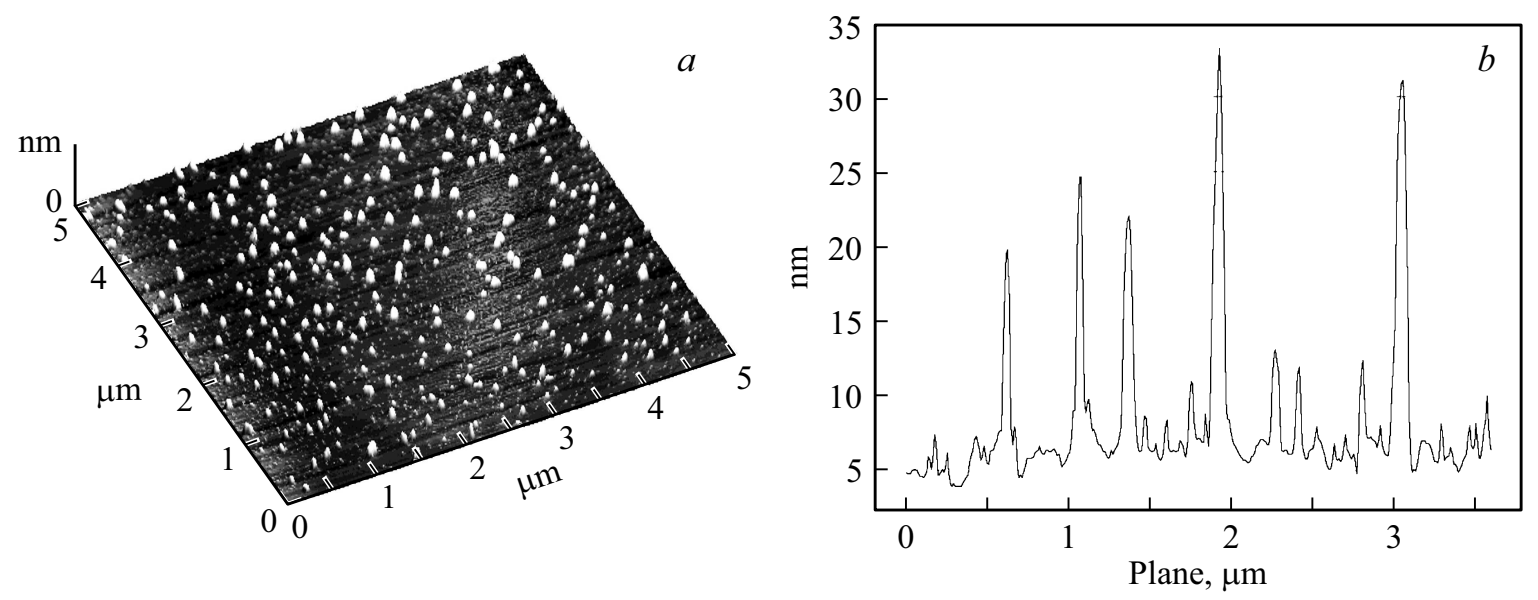

Рис. 3. ACM 3D изображения квантовых точек $\mathrm{MoS}_{2}$ (слева) и сечения профиля этого изображения (справа). 

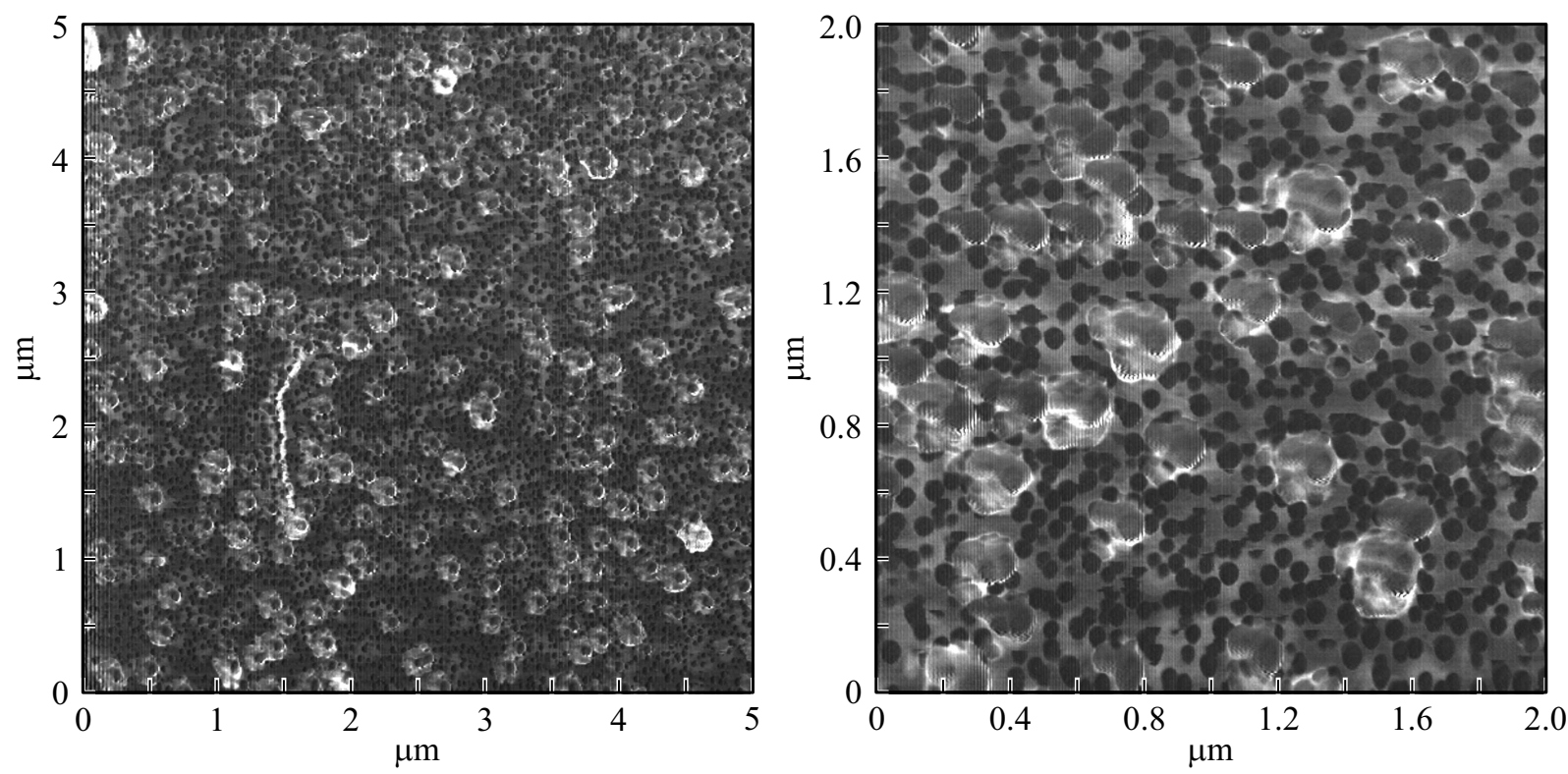

Pис. 4. АСМ-изображения (в двух масштабах) многослойных фракталообразных наноструктр $\mathrm{MoS}_{2}$.

мы (рис. 2) в соответствии с гексагональной симметрией $D_{6 h}$ пленок, содержащей четное число слоев. Размеры гексагональных доменов могут достигать 2-3 мкм по диагонали, как это показано на рис. 2, слева. На некоторых участках верхний слой $\mathrm{MoS}_{2}$ сворачивается в нанотрубки, напоминающие свитки [2], длины которых достигают нескольких десятков мкм (рис. 2, справа).

Далее на рис. 3 приведены ACM 3D изображения квантовых точек $\mathrm{MoS}_{2}$ (слева) и сечения профиля этого изображения (справа). Приведенные на рис. 3 результаты показывают, что квантовые точки среднего диаметра порядка 50 нм самоорганизуются в процессе роста из малых тригональных доменов на средних расстояниях $100-200$ нм.

Один из дальнейших путей самоорганизации многослойных наноструктур $\mathrm{MoS}_{2}$ представлен на рис. 4 .

Здесь в двух масштабах предстают фракталоподобные образования в виде соцветий из субструктур тригональной и гексагональной огранки, самоподобной симметрияи как нечетных, так и четных слоев $D_{3 h}$ и $D_{6 h}$ соответственно.

\section{4. Электронное строение и оптические свойства наноструктур $\mathrm{MoS}_{2}$ различной толщины}

На рис. 5 приведен полученный нами оптический спектр пропускания мономолекулярного слоя $\mathrm{MoS}_{2}$ (верхняя кривая), полученного при температуре $600^{\circ} \mathrm{C}$ на подложке из слюды, морфология которого содержит тригональные домены субмикронных размеров (см. рис. 1).

В спектре отчетливо проявляются три минимума пропускания, соответствующие максимумам поглощения $\mathrm{A}-1.84$ эВ $(675$ нм $), \mathrm{B}-2.00$ эВ (615 нм) и $\mathrm{C}-$
2.78 эВ (445 нм) и одна особенность при энергии 2.37 эВ $(522$ нм). Положения двух первых особенностей А и В хорошо согласуются с оптическими данными для мономолекулярных слоев, приведенными в работе [41] для максимумов А (1.85-1.88 эВ) и В (1.98-2.06 эВ), а также с соответствующими максимумами в спектрах поглощения $(\mathrm{A}-1.89$ эВ $)$ и $(\mathrm{B}-2.03$ эВ) эпитаксиальных мономолекулярных слоев $\mathrm{MoS}_{2}$, выращенных на подложках из слюды в работе [42].

Общепринятая к настоящему времени интерпретация оптических спектров относит две первые полосы А и В к экситонным прямозонным переходам в точке К зоны Бриллюэна мономолекулярного слоя $\mathrm{MoS}_{2}$. Разность

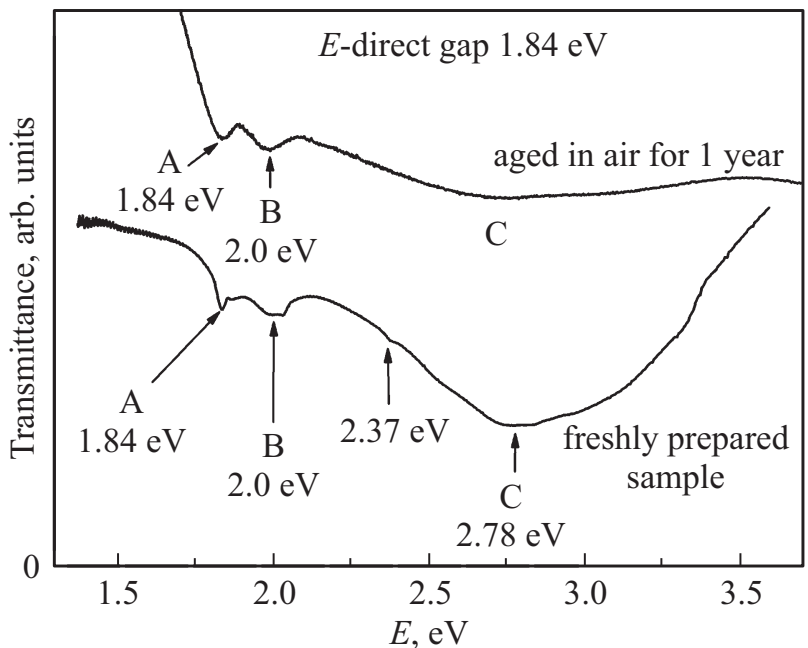

Рис. 5. Оптические спектры пропускания мономолекулярных слоев $\mathrm{MoS}_{2}$. Нижний спектр принадлежит свежеприготовленному образцу, верхний спектр получен от образца после его хранения на воздухе в течение одного года. 

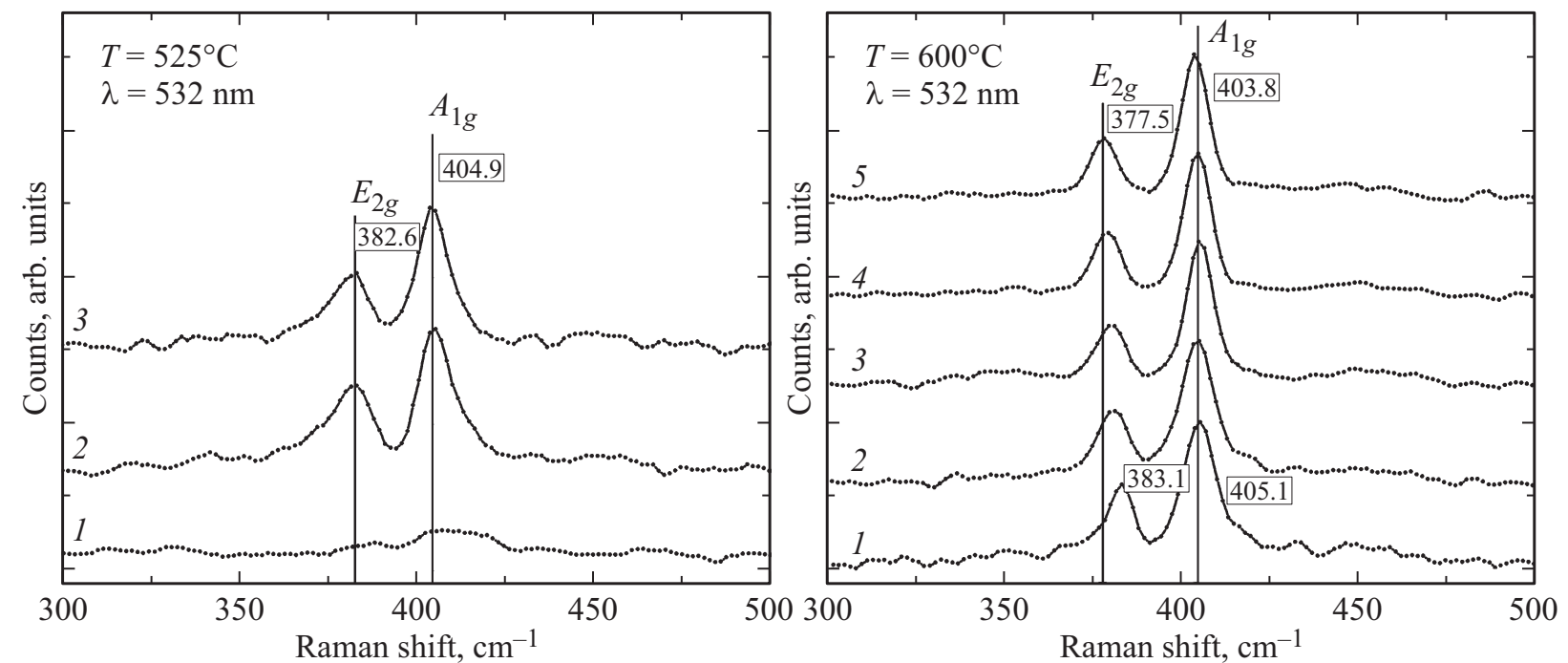

Рис. 6. Рамановские спектры комбинационного рассеяния (КР) мономолекулярных слоев $\mathrm{MoS}_{2}$ (слева) и многослойных наноструктур (справа) в порядке возрастания их толщины от одного слоя (кривая 1) до фракталообразных субструктур (кривая 5), выращенных при температурах $525^{\circ} \mathrm{C}$ (слева) и $600^{\circ} \mathrm{C}$ (справа).

энергий между этими пиками в наших спектрах на рис. 5, равная 0.160 эВ, довольно хорошо согласуется с теоретическим значением 0.148 эВ, рассчитанным для мономолекулярного слоя $\mathrm{MoS}_{2}$ в работе [43].

На рис. 5 приведен второй оптический спектр (нижняя кривая) того же мономолекулярного слоя $\mathrm{MoS}_{2}$, но полученный после пребывания образца на воздухе в течение года. Результаты показывают, что и после столь длительного пребывания на воздухе оптический спектр мономолекулярного слоя $\mathrm{MoS}_{2}$ сохранил основные черты тонкой структуры и по-прежнему показывает экситонные переходы с двумя максимумами А и В при прямозонном переходе. Этот факт свидетельствует о высокой стабильности химических связей $\mathrm{S}-\mathrm{Mo}-\mathrm{S}$ в мономолекулярном слое, не подверженных замещению их связями с кислородом, которая подтвердилась при последующих исследованиях спектров комбинационного рассеяния.

\section{1. Результаты рамановской спектроскопии}

Следует отметить, что большинство спектров комбинационного рассеяния (КР) $\mathrm{MoS}_{2}$, полученных в разных работах, показывает сильные сигналы для мод $E_{2 g}^{1}$ и $A_{1 g}$. При интерпретации результатов следует учитывать, что мода $E_{2 g}^{1}$ обусловлена колебаниями атомов $\mathrm{S}-\mathrm{Mo}-\mathrm{S}$ в плоскости одного мономолекулярного слоя (ковалентноионные связи), тогда как мода $A_{1 g}$ обусловлена колебаниями атомов серы $\mathrm{S}$, перпендикулярными к этим слоям (связи Ван-дер-Ваальса). В работе [44] было обнаружено, что эти две моды демонстрируют сильную зависимость от толщины пленки: при увеличении ее толщины частота моды $E_{2 g}^{1}$ уменьшается (красные смещения), в то время как частота моды $A_{1 g}$ увеличивается (синие смещения) до значений частот этих мод в объемных образцах.
Разность частот составляет около $19 \mathrm{~cm}^{-1}$ для мономолекулярного образца $\mathrm{MoS}_{2}$ и $25 \mathrm{~cm}^{-1}$ для объемного образца. Этот зависящий от толщины сдвиг частот означает, что частоты $E_{2 g}^{1}$ и $A_{1 g}$ можно использовать для определения ультратонкой толщины отдельных слоев $\mathrm{MoS}_{2}$, однако не более чем для четырех слоев [45]. Эти результаты согласуются с данными оптической микроскопии, атомно-силовой микроскопии и измерениями фотолюминесценции [45].

Основываясь на различных опубликованных источниках, авторы работы [42] собрали данные значений частот мод $E_{2 g}^{1}$ и $A_{1 g}$, измеренных в объемном $\mathrm{MoS}_{2}$ и мономолекулярном слое $\mathrm{MoS}_{2}$ при различных длинах волн лазера, которыми можно пользоваться для идентификации мономолекулярного слоя $\mathrm{MoS}_{2}$.

На рис. 6 приведены полученные нами Рамановские спектры КР наноструктур разной толщины в порядке ее возрастания от идентифицируемого мономолекулярного слоя $\mathrm{MoS}_{2}$ (1) до многослойных структур $\mathrm{MoS}_{2}$ (5), выращенных при температурах $525^{\circ} \mathrm{C}$ (слева) и $600^{\circ} \mathrm{C}$ (справа).

Полученные нами максимальные значения для моды $E_{2 g}^{1} 382.6 \mathrm{~cm}^{-1}$ (при $525^{\circ} \mathrm{C}$ ) и $383.1 \mathrm{~cm}^{-1}$ (при $600^{\circ} \mathrm{C}$ ) и минимальные значения для моды $A_{1 g} 404.9 \mathrm{~cm}^{-1}$ (при $525^{\circ} \mathrm{C}$ ) и $405.1 \mathrm{~cm}^{-1}$ (при $600^{\circ} \mathrm{C}$ ) хорошо (с точностью не более $\pm 1 \mathrm{~cm}^{-1}$ ) согласуются с соответствующими значениями 384 и $405 \mathrm{~cm}^{-1}$, приведенными в работе [46] для однослойного $\mathrm{MoS}_{2}$. Поэтому мы считаем, что спектры КР от самых тонких образцов, полученных как при $525^{\circ} \mathrm{C}$ (спектры 1,2 и 3), так и при $600^{\circ} \mathrm{C}$ (спектр 1), принадлежат мономолекулярным слоям $\mathrm{MoS}_{2}$ с тригональной симметрией $D_{3 h}$, морфология которых с тригональными доменами представлена на рис. 1.

Следующий спектр КР (2) при $600^{\circ} \mathrm{C}$ с частотами мод 382.0 и $405.0 \mathrm{~cm}^{-1}$ (рис. 6, справа, кривая 2) принадлежит двуслойному образцу с гексагональной симметрией 
$D_{6 h}$, морфология которого с гексагональными микродоменами представлена на рис. 2.

Третий спектр КР (кривая 3 на правой части рис. 6) принадлежит квантовым точкам, с морфологией, представленной на рис. 3. Значения мод $E_{2 g}^{1}$ и $A_{1 g}$ этих образцов, как и следующих по иерархии фракталоподобных наноструктур, представленных на рис. 4, ближе к значениям этих мод в объемных образцах $\mathrm{MoS}_{2}$ (380 и $406 \mathrm{~cm}^{-1}$ ) из базы данных [47], но отличаются от них. Особенно это относится к внутриплоскостной моде $E_{2 g}^{1}$ фракталообразного образца, имеющей минимальное значение $377.5 \mathrm{~cm}^{-1}$ из всех известных значений для этой моды [42].

Зависимость частоты мод $E_{2 g}^{1}$ и $A_{1 g}$ от толщины слоя $\mathrm{MoS}_{2}$ можно объяснить тем, что по мере увеличения числа слоев усилие по восстановлению межслойных связей $\mathrm{S}-\mathrm{S}$ будет увеличиваться, что соответствует наблюдаемой тенденции увеличения частоты внеплоскостной моды $A_{1 g}$. Одновременное смещение моды $E_{2 g}^{1}$ по мере увеличения числа слоев свидетельствует о том, что внутрислоевые ковалентные связи $\mathrm{S}-\mathrm{Mo}-\mathrm{S}$ также испытывают влияние межслойных связей $\mathrm{S}-\mathrm{S}$, даже таких слабых, как связи Ван-дер-Ваальса.

Поэтому свойства отдельных слоев $\mathrm{MoS}_{2}$ могут отличаться от свойств слоев в объемном $\mathrm{MoS}_{2}$. Такая интерпретация согласуется с измерениями поверхностных явлений, исследованных в работе [48], в которой сообщается о дисперсии поверхностных фононов $\mathrm{MoS}_{2}$, измеренной с помощью спектроскопии потерь энергии электронов высокого разрешения (HREELS). Было обнаружено, что пиковая энергия оптической моды $A_{1 g}$ для тонких слоев на $3.1( \pm 0.2)$ мэВ ниже, чем у соответствующего объемного фонона.

Что же касается внутриплоскостной моды $E_{2 g}^{1}$ фракталообразного образца с минимальным значением частоты $377.5 \mathrm{~cm}^{-1}$, то следует иметь в виду, что это значение относится уже не к слою с 2D размерностью, а к фрактальной структуре с промежуточной размерностью между 2D и 3D.

\section{5. Заключение}

Таким образом, на основании полученных результатов комплексных исследований методами атомной силовой микроскопии, оптической спектроскопии поглощения и рамановской спектроскопии комбинационного рассеяния нанослоев дисульфида молибдена разной толщины, полученных при двух различных достаточно низких температурах показано следующее.

- Методом газотранспортного синтеза в интервале температур 525-600 ${ }^{\circ} \mathrm{C}$ на подложке из слюды (мускавит) получен мономолекулярный слой $\mathrm{MoS}_{2}$, содержащий тригональные домены и обладающий шириной запрещенной зоны 1.84 эВ при прямозонном оптическом переходе с образованием экситонов при комнатной температуре. Оптические свойства таких мономолекулярных слоев сохраняют свои основные характеристики, по крайней мере, по истечению года хранения образцов на воздухе.

- Значение моды внутрислоевых колебаний $E_{2 g}^{1}$ $383.1 \mathrm{~cm}^{-1}$, как и значение моды межслоевых колебаний $A_{1 g} 405.1 \mathrm{~cm}^{-1}$, в мономолекулярном образце с тригональными доменами хорошо согласуется с соответствующими литературными значениями 384 и $405 \mathrm{~cm}^{-1}$ для однослойного $\mathrm{MoS}_{2}$.

- Во фракталообразном образце значения мод внутрислоевых и межслоевых колебаний $E_{2 g}^{1} 377.5 \mathrm{~cm}^{-1}$ и $A_{1 g} 403.8 \mathrm{~cm}^{-1}$ отличаются не только от соответствующих значений мономолекулярного слоя, но и от известных значений объемных образцов $\left(380\right.$ и $\left.406 \mathrm{~cm}^{-1}\right)$. Частота моды внутрислоевых колебаний $E_{2 g}^{1} 377.5 \mathrm{~cm}^{-1}$ в этих образцах имеет минимальное из всех известных значений частот для этой моды, обусловленное промежуточной размерностью фракталообразной субструктуры.

\section{Финансирование работы}

Работа выполнена при поддержке Министерства образования и науки России в рамках государственного задания вузам в сфере научной деятельности на 2017-2019 годы, проекты № 3.6263.2017/ВУ и № 16.8158.2017/8.9.

\section{Конфликт интересов}

Авторы заявляют, что у них нет конфликта интересов.

\section{Список литературы}

[1] K.S. Novoselov, D. Jiang, F. Schedin, T.J. Booth, V.V. Khotkevich, S.V. Morozov, A.K. Geim. Proc. Natl. Acad. Sci. USA, 102, 10451 (2005).

[2] J.R. Schaibley. Nature Rev. Mater., 1, 16055 (2016).

[3] J.A. Jaszczak, M.S. Rumsey, B. Luca, S.A. Hackney, M.A. Wise, C.J. Stanley, J. Spratt. Minerals, 6 (4),115 (2016).

[4] Л.А. Чернозатонский, А.А. Артюх. УФН, 188 (1), 3 (2018).

[5] И.В. Антонова. ФТП, 50 (1), 67 (2016).

[6] Zhang Gong, Huijuan Liu, Jiuhui Qu. Jinghong Li. Energy Environ. Sci., 9, 1190 (2016).

[7] S. Bertolazzi, J. Brivio, A. Kis. ACS Nano, 5 (12), 9703 (2011).

[8] Y. Li, C.M. Araujo, W. Luo, R. Ahuja. Condens. Matter, 1211, 4052 (2012).

[9] J. Feng, X. Qian, C. Huang, W. Li. J. Nature Photonics, 6 (12), 866 (2012).

[10] K.F. Mak, K. He, C. Lee, G.H. Lee, J. Hone, T.F. Heinz, J. Shan. Nature Materials, 12 (3), 207 (2012).

[11] A.A. High, E.E. Novitskaya, L.V. Butov, M. Hanson, A.C. Gossard. Science, 321, 229 (2008).

[12] G. Eda, H. Yamaguchi, D. Voiry, T. Fujita, M.W. Chen, M. Chhowalla. Nano Lett., 11 (12), 5111 (2011).

[13] J.N. Coleman, M. Lotya, A. O’Neill, S.D. Bergin, P.J. King, U. Khan, K. Young, S.A. Gaucher, R.J. Smith, I.V. Shvets, S.K. Arora, G. Stanton, H.Y. Kim, K. Lee, G.T. Kim, G.S. Duesberg, T. Hallam, J.J. Boland, J.J. Wang, J.F. Donegan, J.C. Grunlan, G. Moriarty, A. Shmeliov, R.J. Nicholls, J. M.Perkins, E.M. Grieveson, K. Theuwissen, D.W. McComb, P.D. Nellist, V. Nicolosi. Science, 331 (6017), 568 (2011). 
[14] Z. Zeng, Z. Yin, X. Huang, H. Li, Q. He, G. Lu, G. Boey, F.H. Zhang. Angew. Chem. Int. Ed., 50 (47), 11093 (2011).

[15] H. Li, Z.Y. Yin, Q.Y. He, H. Li, X. Huang, G. Lu, D.W.H. Fam, A.I.Y. Tok, Q. Zhang, H. Zhang. Small, 8, 63 (2012).

[16] Zhang Gong, Huijuan Liu, Jiuhui Qu. Jinghong Li. Energy Environ. Sci., 9, 1190 (2016).

[17] F. Xia, H. Wang, D. Xiao, M. Dubey, A. Ramasubramaniam. Nature Photonics, 8, 899 (2014).

[18] J. Zhang, T. Wang, P. Liu, S. Li, R. Dong, X. Zhuang. M. Chen, X. Feng. Energy Environ. Sci., 9, 2789 (2016).

[19] J.R. Schaibley. Nature Rev. Mater., 1, 16055 (2016).

[20] Intek Сонг, Chibeom Park, Hee Cheul Choi. PCK ADV., 5, 7495 (2015).

[21] R. Ganatra, Q. Zhang..ACS Nano, 8, 4074 (2014).

[22] S. Lebegue, O. Eriksson. Phys. Rev. B, 79, 115409 (2009).

[23] A. Kumar, P.K. Ahluwalia. Eur. Phys. J. B, 85, 186 (2012).

[24] K. Kobayashi, J. Yamauchi. Phys. Rev. B, 51, 17085 (1995).

[25] T. Li, G. Galli,. J. Phys. Chem. C, 111, 16192 (2007).

[26] L. Liu, S.B. Kumar, Y. Ouyang, J. Guo. IEEE Trans. Electron Dev., 58, 3042 (2011).

[27] Y. Ding. Physica B, 406, 2254 (2011).

[28] C.Ataca, H. Çahin, S. Ciraci. J. Phys. Chem. C, 116, 8983 (2012).

[29] R.F. Frindt. J. Phys. Chem. Solids, 24, 1107 (1963).

[30] T. Böker. Phys. Rev. B, 64, 235305 (2001).

[31] R. Coehoorn, C. Haas, R.A. de Groot. Phys. Rev. B, 35, 6203 (1987).

[32] A. Ramasubramaniam. Phys. Rev. B, 86, 115409 (2012).

[33] T. Cheiwchanchamnangij, W.R.L. Lambrecht. Phys. Rev. B, 85, 205302 (2012).

[34] Qing Hua Wang, Kourosh Kalantar-Zadeh, Andras Kis, N. Jonathan, Coleman Michael, S. Strano. Nature Nanotechnology, 7, 699 (2012).

[35] E.S. Kadantsev, P. Hawrylak. Solid State Commun., 152, 909 (2012).

[36] Y.-H. Lee. Adv. Mater., 24, 2320 (2012).

[37] Y. Zhan, Z. Liu, S. Najmaei, P.M. Ajayan, J. Lou. Small, 8, 966 (2012).

[38] Э.П. Домашевская, С.А. Ивков, Аль Хайлани Хасан Исмаил Дамбос, С.В. Рябцев. Конденсированные среды и межфазные границы, 20 (1), 56 (2018).

[39] Е.Д. Мишина, Н.Э. Шерстюк, А.П. Шестакова, С.Д. Лавров, А.С. Семин, С.В. Сигов, А. Митиоглу, С. Ангел, Л. Кулюк. ФТП, 49 (6), 810 (2015).

[40] A. Molina-Sánchez, L. Wirtz, Phys. Rev. B, 84, 155413 (2011).

[41] I. Bilgin, F. Liu, A. Vargas, A. Winchester, M. Ka Lun Man, M. Upmanyu, K.M. Dani, G. Gupta, S. Talapatra, A.D. Mohite, S. Kar. ACS Nano, 1, 23 (2015).

[42] Mingxiao Ye, Dustin Winslow, Dongyan Zhang, Ravindra Pandey, Yoke Khin Yap. Photonics, 2 (289), 288 (2015).

[43] Qingqing Ji, Yanfeng Zhang, Teng Gao, Yu Zhang, Donglin Ma, Mengxi Liu, Yubin Chen, Xiaofen Qiao, PingHeng Tan, Min Kan, Ji Feng, Qiang Sun, Zhongfan Liupubs. Nano Lett., 13 (8), 3870 (2013).

[44] Z.Y. Zhu, Y.C. Cheng, U. Schwingenschlogl. Phys. Rev. B, 84 (15), 153402 (2011).

[45] C. Lee, H.L. Yan, E. Brus, T.F. Heinz, J. Hone, S. Ryu. ACS Nano, 4, 2695 (2010).

[46] Xiao Li Hongwei. J. Materiomics, 1, 33 (2015).

[47] Fluka Chemie AG, Buchs, Switzerland Bio-RAD (SpectraBaseSpectrum ID GwfzYmPOMYR).

[48] P. Bertrand. Phys. Rev. B, 44, 5745 (1991).

\section{Featires of the morphology and optical properties of molybdenum disulfide nanostructures from a monomolecular layer to the fractal like substructure}

\author{
E.P. Domashevskaya, D.L. Goloshchapov, Al Khailani \\ Hasan Ismail Dambos, E.V. Rudnev, \\ M.V. Grechkina, S.V. Ryabtsev
}

\section{Voronezh State University, 394006 Voronezh, Russia}

\begin{abstract}
The aim of the work is to show the effect of layer thickness on the feautures of the morphology and optical properties of $\mathrm{MoS}_{2}$ nanistructures, including the monomolecular layers, formed during the gas transporting transfer of sulfur vapors to the reactor hot zone with a molybdenum metal and subsequent deposition on the mica (muscavite) substrates. The results of the atomic force microscopy, optical absorption spectroscopy and Raman spectroscopy of molybdenum disulfide nanostructures of different thickness, obtained in temperatures interval of gas transport synthesis $525-600^{\circ} \mathrm{C}$, show that a monomolecular $\mathrm{MoS}_{2}$ layersm containing trigonal domains and having a width of the band gap $1.84 \mathrm{eV}$ at a direct-gap optical traansition with the formation of excitons at room temperature, can be obtained. For the first time, fractal-like substructures were obtained, in the Raman spectra of which the values of the modes of intralayer and interlayer oscillations $E_{2 g}^{1} \quad 377.5$ and $A_{1 g} \quad 403.8 \mathrm{~cm}^{-1}$ differ not only from the corresponding values of the modes of the monomolecular layer, but also from the known values of bulk samples. The frequency of the intralayer mode in these samples, $E_{2 G}^{1} 377.5 \mathrm{~cm}^{-1}$, is the smallest of all known values.
\end{abstract}

